\title{
The Effects of Socio-Affective Strategy in the Enhancement of Reading Comprehension among Iranian EFL Learners
}

\author{
Siamak Zeynali, Simin Zeynali, Seyyed Fariborz Pishdadi Motlagh* \\ Department of Foreign Languages and Literature, University of Tabriz, Tabriz, Iran \\ Email address: \\ siamak_323e52@yahoo.com (S. Zeynali), simin_zeynali2000@yahoo.com (S. Zeynali), Fpishdadi@Yahoo.com (S. F. Pishdadi Motlagh)
}

To cite this article:

Siamak Zeynali, Simin Zeynali, Seyyed Fariborz Pishdadi Motlagh. The Effects of Socio-Affective Strategy in Enhancement of Reading Comprehension in Iranian EFL Learners. International Journal of Language and Linguistics. Special Issue: Applied Linguistics and English Language Teaching Methodologies in All Fields. Vol. 4, No. 2-1, 2015, pp. 9-22. doi: 10.11648/j.jill.s.2016040201.12

\begin{abstract}
This study aimed to investigate the effects of socio-affective strategies in the enhancement of reading comprehension in Iranian EFL learners. For this purpose, the study adopted a quasi-experimental design with a proficiency test to find the homogeneity of groups. Furthermore, two classes were selected as the experimental and control groups ( $\mathrm{n}=60$ ), and the experimental group was conducted by social-affective strategies items. Participants attended in six sessions of the making learners familiar with advantages of social-affective strategies and their effects on improvement of learners' reading comprehension. Experimental group received different strategies and its sub categories. Then, the researcher taught and employed those strategies by applying them in reading comprehension texts. Learners' activities and their strong interest showed that they like teaching by employing socio/affective strategies and the progress was measured during the six sessions of employing those strategies in responding to reading questions. An independent t-test, paired sample, and ANCOVA, procedures were applied to find the results in statistics and showed that socio/affective strategies were effective and as a fostering issue in enhancing the learners' awareness to respond the questions compared to control group that was without any treatment. These outcomes show that using socio/affective strategies were more helpful factor for learners to answer the reading comprehension questions.
\end{abstract}

Keywords: Language Learning Strategies, Social-Affective Strategy, Reading Comprehension

\section{Introduction}

Learning a second or foreign language requires the manipulation of four main skills, namely, listening, reading, speaking, and writing which lead to effective communication. Learning to read is a very complex developmental process that begins at birth. It is also a process that presents many challenges to learners. For second and foreign language learners who are learning to read in English, the process presents additional challenges because the linguistic and cultural backgrounds of these learners are different from the language and culture embedded in the reading process. It is obvious that reading comprehension is an indispensible part of any education English reading classes in Iran institutes often end up with teacher led translations, resulting in a lack of interaction between the teacher and students and among students themselves. The lack of interaction in turn leads to a more serious problem that is depriving students of the opportunity to gain useful feedback to check and correct their understanding of the reading materials. Due to the lack of feedback, they are often unaware of how well they are understanding the material, what mistakes they are making and what problems they are having. Proficiency in reading involves many variables, for example, automaticity of word recognition, familiarity with text structure and topic, awareness of various reading strategies, and conscious use and control of these strategies in processing a text (Pang, 2008).

One of the fundamental prerequisites for reading is the knowledge of language. It is common knowledge that reading in English is an active skill requiring reader to deal with a variety of complicated tasks. It is also known that reader use a variety of mental processes to give meaning to the information they read to. The mental processes that reader use to understand spoken English can be broadly described as reading comprehension strategies (Gibson, 2010). There seems to be a common feeling among L2 reading researchers that reading should be approached as a 
skill requiring strategy use and teaching students how to use these strategies leads to improvement in their reading ability. Reading is the process of constructing meaning through the dynamic interaction among the reader's existing knowledge, the information suggested by the written language, and the context of the reading situation (OSPI, 1998). As indicated by Devine (1988), "Reading is an act of creation the meaning emerge a new in each encounter of a reader with the text" (p.260). In each reading situation the reader needs to possess two kinds of knowledge: (a) the knowledge of the language, which Eskey (1986) calls the "formal knowledge;" and (b) the "knowledge of the substance," or the content information (Eskey, 1986, p.17). Reading is also a very complex process that presents many challenges to learners learning to read. For a better understanding of reading strategies, especially social affective ones, it is necessary to explain and categorize language learning strategies first. In this study, learning strategies are "behaviors or actions which learners use to make language learning more successful, self-directed, and enjoyable" (Oxford, 1989, p. 235) and they can be categorized under three main groups as listed below (O'Malley et al., 1985, p. 582-584) a) Cognitive strategies (e.g. repeating, translation, grouping, note taking, deducting, imagery, auditory representation, key word, contextualization, elaboration, transfer). b) metacognitive strategies (e.g. planning for learning, thinking about the learning process as it is taking place, monitoring of one's production or comprehension, and evaluating learning after an activity is completed). c) Socio/ affective strategies (e.g. socialmediating activity and transacting with others). Socio/affective strategies are those which are non-academic in nature and involve stimulating learning through establishing a level of empathy between the instructor and student. They include considering factors such as emotions and attitudes (Oxford, 1990).

Socio-affective strategies strongly consider the student's relation to society as a whole ranging from family to the global community. Among these strategies, socio/affective strategies are considered as the most essential ones in developing learners' skills (Anderson, 1991). On the other hand, learners who have developed their socio/affective strategies are likely to become more successful language learners (Hauck, 2005). There are many factors involved when trying to understand what makes a person learn a foreign language successfully (Wenden and Rubin, 1987; Chamot and O'Malley, 1994). However, humanistic language teaching has indicated that affective factors, such as attitudes, motivation, anxiety, and self-esteem, have great influence on the success of language learning since "the way we feel about our capacities and ourselves can either facilitate or impede our learning" (Arnold and Brown, 1999, p. 8). In the same research, Andres (2002) argues that "if we want our students to develop their inherent potential to learn, the affective variables such as anxiety, motivation, self-esteem and inhibition and the inner needs of the learners can no longer be neglected" (p. 97). Previously, Oxford and Ehrman (1993) had pointed out, "many excellent teachers have learned to do some of this intuitively, but explicit understanding of individual-difference dimensions can enhance the work of all teachers" (p. 188).

Similarly, Chamot (2005), asserted that less successful language learners do not have the socio/affective knowledge needed to select appropriate strategies. Goh (2002), emphasizes the importance of socio/affective strategies by arguing that learners' socio/affective strategy is related to effective learning in all learning contexts. Goh and Yusnita (2006), draw attention to the specific context of L2 reading and claim that strategies have a direct and positive influence on reading performance. Yang (2009) also indicates that one of the distinctive features differentiating successful readers from unsuccessful ones is their use of socio/affective strategies and he supports the idea that teaching the role of socio/affective in L2 reading helps readers to approach the reading task more effectively. As Luo-xiang (2005) concludes, more discussion is needed to increase learners' socio/affective strategies in reading. In the light of this research, the aim of this study is to research the effect of socio/affective strategy and its effect on reading performance. This study has the main objective to review relevant literature about the effect of socio/affective strategy instruction on $\mathrm{L} 2$ reading comprehension.

Research Questions:

RQ1: Are there any differences between control and experimental groups on the result of placement test?

H01: There are no differences between control and experimental groups on the result of placement test.

H1: There are differences between control and experimental groups on the result of placement test.

RQ2: Are there any differences between pre-test and posttest results on control groups on reading comprehensions?

H02: There are no differences between pre-test and posttest results on control groups on reading comprehensions.

$\mathrm{H} 2$ : There are differences between pre-test and post-test results on control groups on reading comprehensions.

RQ3: Are there any differences between pre-test and post test results on experimental groups on reading comprehensions?

H03: There are no differences between pre-test and post test results on experimental groups on reading comprehensions.

H3: There are differences between pre-test and post-test results on experimental groups on reading comprehensions.

RQ4: Is there any relationship between social/affective strategies as positive strategy on reading comprehension?

H04: There is no relationship between social/affective strategies as positive strategy on reading comprehension.

H4: There is relationship between social/affective strategies as positive strategy on reading comprehension.

\section{Review of the Related Literature}

\subsection{Reading Comprehension}

The notion of reading to learn first received attention in the 
ESL field in the late 1970s and early 1980s with the writings of Stephen Krashen. (Seefor example, Krashen, 1976, 1977; Krashen \& Terrell, 1983) Researchers focusing on this issue with adult English language learners include, among others, Brown (1993); Chervenick (1992); Joe (1998); Lantigne \& Schwartzer (1997); Mikulecky (1992); Perfetti, Britt, \& Georgi (1995); Petrimoulx (1988); and Tse (1996a, 1996b). Their hypothesis is that second language learners need extensive access to language that they can understand but is more difficult for them to produce. In other words, they need comprehensible input (Krashen \& Terrell, 1983). Reading texts can provide one source of comprehensible input. Therefore, researchers have hypothesized that reading texts that are comprehensible can have a positive impact on second language acquisition.

Reading comprehension have been a widely studied as controversial issue for years. Although here have been quite a number of investigations concerned with this subject, what differentiates one from another is its approach. It is true that the context in which the study is developed makes it unique in time, place and the participants' individual differences. Comprehension is considered as the main aim of reading and involves three factors such as the reader, the text, and the context in which the text is read. However, no one can reaches comprehension, perhaps there is a lack of interest from the reader, so the text could not be regards as an appropriate or simply the reader does not use the strategies needed to obtain meaning. Being aware of reading comprehension strategies will make students become effective readers thanks to cognitive, metacognitive and socio/affective processes. Hedge (2003), asserts that any reading component of an English language course may involve a set of learning goals for the competence to read a wide range of texts in English. This is the long-range goal most teachers search to develop through independent readers outside EFL/ESL Classroom. Building knowledge of language, which will make smooth reading ability, Building schematic knowledge, the dexterity to adapt the reading style according to reading purpose (i.e. skimming, scanning), Expand an awareness of the structure of written texts in English, taking a critical stance to the contents of the texts.

Reading comprehension is defined as the level of understanding of a text/message. This understanding comes from the interaction between the words that are written and how they trigger knowledge outside the text/message. Reading theories take place when students use strategies in reading. They are known as bottom-up strategies and top down-strategies. First, before going into reading comprehension strategies, it is important to define learning strategies. As cited in Castello, 2002), the fact of having learning strategies involves making decisions intentionally and voluntarily about how to behave in order to achieve a specific learning objective. Reading strategies let students decide on how to read, taking into account their own objectives plus the characteristics of the text (p. 191). Over decades, there have been various definitions and explanations on reading concept. The importance of reading has been unveiled to many researchers and readers. This is why Strang (1967) stated, reading is the "royal road" to knowledge. Reading is essential to success especially in academic subjects. In this modern era, learning heavily depends on ability of the readers to interpret the printed pages accurately and clearly.

According to De beaugrande \& Dressler (1981), communicative texts show cohesion, coherence, intentionality, acceptability, informatively, situationality and intersexuality.

- Cohesion refers to the relationship between text and syntax, that is, how the elements of the text are connected in a progressive sequence.

- Coherence refers to the meaning of the text that can be reached by applying cognitive processes.

- Intentionality has to do with the attitude and purpose of the writer.

- Acceptability concerns the preparation of the reader to evaluate the relevance of a given text.

- Informatively is related to quantity and quality of new or expected information.

- Situationality refers to the situation in which the text is and plays an important role in the production and reception of the message.

- Intersexuality refers to the fact that the reader needs to know about other text genres such as narrative texts, argumentative texts, descriptive texts, etc.(as cited in Catenaccio,2010)

These principles have a big impact on the field of reading comprehension in a second language because interaction occurs between the writer, who produces, and the reader receiving and constructing meaning. It also should be emphasized that the reading process is linked to everyday situations, and meaning depends on the social context too. Finally, it is important to bear in mind how suitable the text is in order to exploit it effectively, supplement it if necessary, and perhaps argue the case for its replacement. Proficient reading depends on the ability to recognize words quickly and effortlessly. If word recognition is difficult, students use too much of their processing capacity to read individual words, which interferes with their ability to comprehend what is read.

\subsection{Reading and Socio Affective Strategies}

Learning strategies are divided into three main categories: metacognitive, cognitive and socio affective (O’Malley\&Chamot, 1990). While learners use cognitive strategies to achieve a particular goal, say, understanding a text, metacognitive strategies are used to ensure that the reader has successfully done the activity after it is completed (Living Stone, 1997). Socio affective strategies, On the other hand, deal with learners' interactions with others (Brown, 2000). Unlike self-efficacy, learning strategies, generally, and reading strategies, particularly, have been the focus of a wealth of studies. Reading strategies were defined as "deliberate, conscious procedures used by readers to enhance text comprehension" (Sheory\&Mokhtari, 2001, p.433). The 
purpose of reading strategies are to have general knowledge, to get a specific detail, to find the main idea or theme, to learn, to remember, to delight, to summarize and to do research(Hylland, 1990). Regarding the importance of reading strategies, Pressly and Afflerbach (1995) identified several key strategies that were evident in the verbal protocols they reviewed including:

a) Overview before reading;

b) Look for important information and pay greater attention to it;

c) Relate important points to one another;

d) Activate and use prior knowledge;

e) Change strategies when understanding is not good; and

f) Monitor understanding and take action to correct inaccuracies in comprehension.

Concentrating on differences concerning the way and number of reading strategies, Richards (2002) argues that the use of wellchosen strategies distinguishes experts from novices in many learning areas. Pressly (2000) and Wade (1990) believe that good readers apply a variety of appropriate strategies to the text they are reading. Implying the crucial importance of reading strategies, some studies support the effectiveness of reading strategies instruction (Dreyer\&Nel, 2003; Kern, 1989; Meng, 2004) whereas others indicate futility of reading strategies instruction (Barnett, 1988; White, 2006). Contrary to traditional cognitive views, current views on reading development recognize the relevance of socio-affective factors. Anderson (1999) includes building motivation in his strategies for teaching second language reading. Greaney (1996) argues for reading instruction to focus more on instilling joy and pleasure in learners than on teaching cognitive skills. Verhoeven and Snow (2001 p.2) argue that, without some level of motivation, neither orthographic knowledge nor comprehension strategies are likely to develop optimally.

Serpell (2001), Street (2001) and Niven (2005) all acknowledge the influence of social factors in reading development, and argue for socio-cultural underpinnings to literacy development. Bus (2001) highlights the social aspect of reading development strongly in his study. He shows from his study that the interactive experience that children receive from their parents affects the frequency and quality of parentchild book reading and, consequently, the development of literacy. Grabe and Stoller (2002,p.37) concede that: This emphasis on individual processes is not intended to deny the relevance of social factors on reading development (e.g. family literacy experience, primary schooling, and peer and sibling interaction around literacy events) or the relevance of social contexts on purpose and processes them.

Guthrie and Wigfield (2000,p.404) sum up these arguments when they state that, 'readers are decision makers whose affects as well as their language and cognition play a role in their reading practices'. Despite social and affective factors having been acknowledged as important in reading development, there is, however, little research in this area. There is no doubt that social and affective issues are considered as relevant in students' reading development.
However, this has not been transferred to practical teaching.

Greaney (1996) and Elley (1996) lament that many teachers, especially in developing countries, still focus solely on skills in reading instruction. A number of reading intervention programmers', both nationally and internationally, are cognitively oriented, focusing mainly on skills such as word recognition, strategy use, reading speed and vocabulary development.

Besides, being largely excluded in reading instruction, socio-affective factors have not been researched extensively in reading development (Grabe \& Stoller, 2002; Brunfaut, 2008). Grabe and Stoller (2002,p.57), in discussing the influence of socio-affective factors in reading development, state for instant no one disputes the fact that students' selfperceptions, emotional attitudes towards reading, interest in specific topics, willingness to read texts and learn from them are important issues for the classroom-learning environment.

\subsection{Social Affective Strategies}

It means, learning by interacting with others, such as working with fellow students or asking the teacher's help. The powerful social and affective strategies are found less often in L2 research. This is, perhaps, because L2 researchers do not study these behaviors frequently, and because learners are not familiar with paying attention to their own feelings and social relationships as part of the L2 learning process (Oxford, 1990).

As to the socio/affective strategies, it can be stated that they are related with social-mediating activity and transacting with others. Cooperation and question for clarification are the main social /affective strategies. Affective strategies, such as identifying one's mood and anxiety level, talking about feelings, rewarding oneself for good performance, and using deep breathing or positive self-talk, have been shown to be significantly related to L2 proficiency in research by (Magno, 2010).

However, in other studies, such as Oxford (2003) affective strategies showed a negative link with some measures of L2 proficiency. One reason might be that as some students progress toward proficiency, they no longer need affective strategies as much as before. Perhaps because learners' use of cognitive, metacognitive, and social strategies is related to greater L2 proficiency and self-efficacy, over time there might be less need for affective strategies as learners' progress to higher proficiency.

\subsection{Social Factors}

Social strategies for example asking questions to get verification, asking for clarification of a confusing point, asking for help in doing a language task, talking with a native-speaking conversation partner, and exploring cultural and social norms help the learner work with others and understand the target culture as well as the language. Social strategies deal with the people surrounding the learner and the environment as well. Social strategies lead to increased interaction with the target language. Social strategies are 
activities which give them opportunities to be exposed to and practice their knowledge as described by (Hismanoglu, 2002). Social strategies (e.g., asking questions to get verification, asking for clarification of a confusing point, asking for help in doing a language task, talking with a native-speaking conversation partner, and exploring cultural and social norms) help the learner work with others and understand the target culture as well as the language. Social strategies were significantly associated with L2 proficiency in studies by the South African EFL study by Dreyer and Oxford (1996) and the investigation of native-English-speaking foreign language learners by Oxford and Ehrman (1995).

According to Habte-Gabr (2006) socio-affective strategies are those which are non-academic in nature and involve stimulating learning through establishing a level of empathy between the instructor and student. They include considering factors such as emotions and attitudes (Oxford, 1990). Socioaffective strategies strongly consider the student's relation to society as a whole ranging from family to the global community. Similarly, Vandergrift defines socio-affective strategies as the techniques listeners use to collaborate with others, to verify understanding or to lower anxiety (Vandergrift, 2003).

\section{Design of the Study}

In this research a proficiency test used to making clear that all of the students are homogenous and they are in the same level. After administrating the proficiency test, experimental classes which were lasted for 3 weeks treated with social/affective strategies in the all first half times of the class then the groups received reading passages that were taught and exposed during course and taught them with socio affective strategies instructions including social/affective strategies instructions. Every session students were familiarized with some of the sub categories of socio affective strategy and it was clearly obvious that these strategies were paid more attention from learners' side. Relaxation, rewarding, discussing feelings with others in affective and asking for correction, cooperating with others, to become aware of others feelings are obvious in social strategies. These findings were important, so learners liked to use and apply them, because of their easiness and interest and being trendy and perfectly comprehensible among them. Having answered the required tests and questions, the elicited data statistically analyzed and interpreted. At the end of the course experimental groups' results of the test were comparing the effect of the training.

\subsection{Materials}

An already settled standard placement test of Oxford university and Cambridge university (2001, version 1) was used to divided the participants into intermediate levels. This instrument included 60 multiple - choice question, cloze comprehension passage, vocabulary, and grammar sections. Furthermore, five reading passages extracted from the TOEFL Test by Deborah Philips published by Hanshin
University press, and some supplements applied by researcher and evaluated in order to find first, which group, the experimental or control, improved in their ability to translate clauses and second, which group increased the number of words translated correctly finally, which group showed a greater improvement in the TOEFL test.

\subsection{Procedures}

After administering the homogeneous test, the treatment sessions involving teaching and explaining of socio affective strategies that each groups has some significant and prominent branches discussed and elaborated during the 6 sessions then five reading comprehension passages with 50 multiple questions accompanied with every learning strategies training, started and evaluated. During the treatment period, the teacher provided the most noticeable and useful strategies of each main strategy as was mentioned, such as ,relaxation, rewarding, discussing feelings with others in affective and asking for correction, cooperating with others, becoming aware of others feelings in social strategies. Then in order to measure the different effects of the socio affective strategies on promoting of L2 learners reading comprehension, the descriptive statistics including mean scores, standard deviation and etc. for each group's accurate use of the social/affective strategy was presented and illustrated in the tables of descriptive statistics vividly.

The present study aimed to illustrate that the affection of social/affective strategies as positive factor on enhancing L2 learners reading comprehension and which group increased the number of words translated correctly. By applying this strategy researcher wants to find the significance of using social/affective strategies among students, also to infer that which of them is greater improvement in the TOEFL test. Having discussed and applied the above tests, the following statistical procedures were used. Data was analyzed through applying Statistical Package for the Social Sciences (SPSS) based on Windows Version 11.0. A homogenous test, an independent t-test, paired sample, and ANCOVA, was applied to answer research question. Descriptive statistics (frequency, mean, and standard deviations) were used to examine the overall strategy use, by taking Brown's (2000) three classifications.

In this research, socio affective strategy was used as independent variables, whereas reading comprehension was regarded as dependent variable. To fix whether there were noticeable effects in the use of socio affective strategy and reading comprehension in upper intermediate levels. ANCOVA procedures were handled. By referring to the results of ANCOVA, the effects of socio affective strategy training on reading comprehension were determined.

\subsection{Instructional and Testing Procedures}

After the participants and the materials were chosen, the procedure commended. Although all participants were at the upper intermediate level, before conducting the classes a standard placement test of Oxford university and Cambridge 
university (2001, version 1 ) was administrated as a proficiency test and it includes 60 multiple-choices question, cloze comprehension passages, vocabulary, and grammar sections. It was used and those who scored 30-40 were selected as the participants of the study. This way of selection of participants made us certain about their homogeneity. During of treatments, the social/affective strategies were discussed especially the most prominent points in strategy. When all participants completely be awarded of socio affective strategy, 5 reading comprehension passages selected from TOEFL books with 50 questions distributed among learners and finally papers were corrected and the scores were $\mathrm{X}$ of 50, and (ANCOVA) showed the statistics results. The instructional treatments were provided during six training sessions, each of which lasted approximately 45 minutes. Every session the instructions distributed to learners similar to all the experimental groups. This normal instruction lasted about 45 minutes, (30 minutes training and 15 minutes testing). In every sessions of the study, which was accompanied with explaining and analyzing the socio affective strategy, all participants were assigned to understand and ask their questions. In other words, while in each session of the treatment participants within each group were to make understood about socio affective strategy. In addition to these differentiations, the experimental groups differed in terms of learning strategy; while the first experimental group's members received socio affective strategy instructions, the second experimental group's members didn't received socio affective strategy instructions.

\section{Data Analysis and Results}

Table 1. Descriptive statistics of experimental and control groups on the placement test by T-Test.

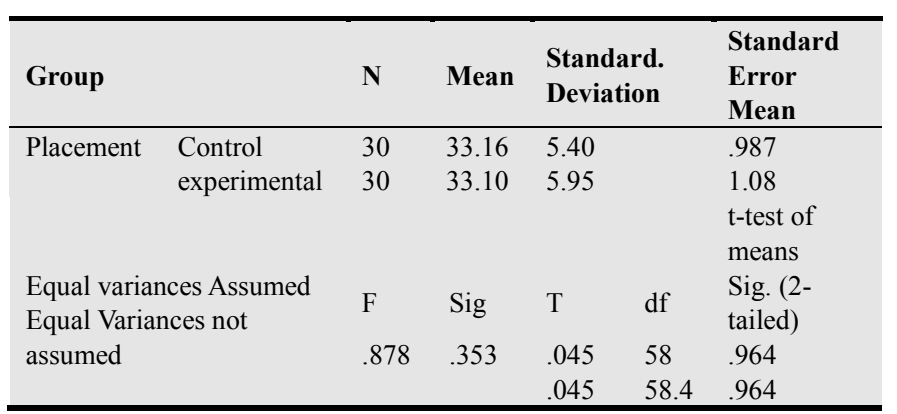

Table 1 classifies the mean and standard deviation of learner's placement test in experimental and control groups. As we know the t-test will be used when one wants to determine if the means of two groups are significantly different from one another or when we want to compare two groups at the same time. Here we have two groups that are experimental and control groups. Table 1 demonstrates the results are expressed as mean $\pm \mathrm{SD}(n=60)$. According to the descriptive findings, the first variable is the control groups $(33.16 \pm 5.40)$. The second variable is experimental groups which mean and standard deviations are respectively (33.10 $\pm 5.95)$.
In the present study, the significant levels are $p>0.05$. According to the table 1 and based on the T-Test which is used in this stage, it is observed that significant of control and experimental groups are sig $=.964$, so it could be inferred that there is no noticeable differences exist among control and experimental groups at the same time in placement test.

RQ: Are there any differences between control and experimental groups on the result of placement test?

H0: There are no differences between control and experimental groups on the result of placement test.

$\mathrm{H}$ : There are differences between control and experimental groups on the result of placement test.

Table 2. Paired sample statistic of experimental groups on pre-test and posttest.

\begin{tabular}{lll}
\hline & Pre mark & Post mark \\
\hline N valid & 30 & 30 \\
Missing & 0 & 0 \\
Mean & 27.6 & 42.1 \\
Std. deviation & 4.7 & 6.24 \\
Skewness & .82 & -392 \\
Std. error of skewness & .42 & .42 \\
Range & 20 & 21 \\
Minimum & 20 & 29 \\
Maximum & 40 & 50 \\
\hline
\end{tabular}

Table 2 classifies the mean and standard deviation of experimental group on the pre-test and post-test. As it is shown, the pretest' mean and standard deviation are respectively 27.66 and 4.7 and post-test' mean and standard deviations' are 42.1 and 6.2. The socio/affective strategy which was used for the pre-test included realizing problems which they face, formulate question, and ask the teacher or peers were posed to the students as socio/affective activities. On the other hand, table 2 shows experimental learners with a mean of 42.1 and standard deviation of 6.2 is highly improved on the post-test. The most frequent score in the pre-test (27.6) changed to (42.13) in the post -test. After the treatment students involved in pre-socio/affective activities then, the mean score of the students in the post-test increased to 42.1. As the results indicated, the students in the experimental group achieved a higher mean score on the post-test. Table 2 outlines that the participants in experimental group had significantly increased their scores in the post-test. As the achieved significance was less than 0.05 , the null hypothesis was rejected, that is the means on pre-test and post-test were significantly different to support the claim that socio/affective strategy can enhance reading comprehension ability and it is as a positive predictors among L2 learners.

RQ: Are there any differences between pre-test and post test results on experimental groups on reading comprehensions?

H0: There are no differences between pre-test and post test results on experimental groups on reading comprehensions.

$\mathrm{H}$ : There are differences between pre-test and post-test 
results on experimental groups on reading comprehensions.

Table 3. Paired sample statistic of control groups on pre-test and post-test

\begin{tabular}{lll}
\hline & Pre mark & Post mark \\
\hline Nvalid & 30 & 30 \\
missing & 0 & 0 \\
Mean & 28 & 28 \\
Std. deviation & 5.8 & 5.97 \\
Skewness & .62 & 659 \\
Std.error of skewness & .42 & .42 \\
Range & 19 & 20 \\
Minimum & 20 & 20 \\
Maximum & 39 & 40 \\
\hline
\end{tabular}

Table 3 demonstrated that the mean and standard deviation of control group on the pre-test and post-test. As it is shown, the pretest' mean and standard deviation are respectively 28 and 5.8 and post-test' mean and standard deviations' are 28 and 5.9. On the other hand, table 3 shows control learners with a mean of 28 and standard deviation of 5.8 is not improved on the post-test. The most frequent score in the pre-test (28) doesn't change in the post -test. As the results indicated, the students in the control group don't achieve a higher mean score on the post-test. Table 3 outlines that the participants in control group had not increased their scores in the post-test.

The results of paired table for post-test in Tables $(2,3)$ indicate that there was a significant difference between the two groups in their final test. According to the data in Tables $(2,3)$ the experimental group considerably outperformed the control group in the post-test. The results indicate that socioaffective strategy training had been effective influence in improving students' score in the experimental group.

RQ: Are there any differences between pre-test and posttest results on control groups on reading comprehensions?

H0: There are no differences between pre-test and post-test results on control groups on reading comprehensions.

$\mathrm{H}$ : There are differences between pre-test and post-test results on control groups on reading comprehensions.

In order to test the normality of distribution, we performed the one-sample Kolmogorov-Smirnov Tests shown in Table 4 for pre-post percent scores.

Table 4. The Results of Kolmogorov-Smirnov Test for pre-test and post-test Scores in two Groups.

One-Sample Kolmogorov-Smirnov Test

\begin{tabular}{|c|c|c|c|}
\hline & & PREMARK & POSTMARK \\
\hline $\mathbf{N}$ & & 60 & 60 \\
\hline \multirow[t]{2}{*}{ NORMAL PARAMETERS } & Mean & 27.8333 & 35.1000 \\
\hline & Std. Deviation & 5.28563 & 9.32956 \\
\hline Most Extreme & Absolute & .158 & .124 \\
\hline \multirow[t]{2}{*}{ Differences } & Positive & .158 & .124 \\
\hline & Negative & -.089 & -.114 \\
\hline Kolmogorov-Smirnov Z & & 1.221 & .963 \\
\hline Asymp. Sig (2-tailed) & & .102 & .311 \\
\hline
\end{tabular}

a. Test distribution is Normal

b. Calculated from data

Moreover, Table 4 shows that the K-S tests of the transformed data are all significant, showing that the distributions approximate the normal distribution more closely. On the hand Results of Kolmogorov-Smirnov Test for pre-test and post-test Scores in two Groups before conducting ANCOVA test, the researchers used the Kolmogorov-Smirnov test to check the normality of the distribution of data. Results of Kolmogorov-Smirnov test for pre-test and post-test of control and experimental groups is $\mathrm{p}>0.05$, so the distribution of data is normal. On the other hand, the significance of each Kolmogorov-Smirnov test conducted to tests results in both groups is higher than .05 , it was concluded that the scores obtained from all the tests follow a normal distribution.

The ANCOVA statistical method was selected for the measurements of experimental and control group's means in reading comprehension ANCOVA is used to test the main and interaction effects of the factors, while controlling for the effects of the covariates. ANCOVA has four assumptions: Normality, equality of variances, homogeneity of slopes, and independency of scores on the dependent variable. Firstly, a test was carried out to determine whether ANCOVA's assumptions had been met. The pre-test achievement and reading comprehension scores of the groups were then tested to determine whether there were any significant differences. The students' post-test mean achievement scores adjusted according to the pre-test achievement and self-efficacy scores are presented in Table 6 The ANCOVA test results carried out to determine whether there were any significant differences between the groups in terms of their adjusted post-test mean achievement scores. According to the ANCOVA results, it was found that there was a significant difference between the post-test mean achievement scores adjusted according to the pre-test achievement and self-efficacy scores of the students in the separate groups. The results of the ANCOVA for the pre-test scores and the three weeks post test scores on selected skill performance variables, after the three weeks experimental training programs, results presented in tables 4 and 5. Due to the importance of pretest, Covariance was used for investigating hypothesis of the study. At first, we examine between covariate variable and dependent variable exist linear relationship and homogenous regression so we can run covariance. In table 5 the Covariance related to the experimental and control groups of 60 students in each group 
are presented.

Table 5. Dependent subject effects of socio/affective strategy for comparing the results of post-test.

Tests of Between-Subjects Effects

Dependent Variable: POSTMARK

\begin{tabular}{lllllll}
\hline Sources & Type III Sum of Squares & df & Mean Square & F & Sig. & Partial Eta Squared \\
Corrected Model & $3908.370 \mathrm{a}$ & 2 & 1954.185 & 90.779 & .000 & .761 \\
Intercept & 406.232 & 1 & 406.232 & 18.871 & .000 & .249 \\
PREMARK & 940.303 & 1 & 940.303 & 43.680 & .000 & .434 \\
GROUP & 3072.206 & 1 & 3072.206 & 142.715 & .000 & .715 \\
Error & 1227.030 & 57 & 21.527 & & \\
Total & 79056.000 & 60 & & & \\
Corrected Total & 5135.400 & 59 & & & \\
\hline
\end{tabular}

a. $\mathrm{R}$ Squared $=.761$ (Adjusted R Squared $=.753)$

Table 5 demonstrates the results of the analysis of covariance for investigating the effects of socio/affective strategy on the reading comprehension, there is a significant difference between the effect of socio/affective strategy on reading comprehension on experimental group in comparison with the other group $(\mathrm{P}<0.05)$. On the other hand, the significance of the test equals .000 which is lower than 0.05 . This indicates that the pre-test and post-test are statistically and meaningfully different from each other regarding their general English proficiency level. Finally, results indicated that the teaching of socio/affective strategy increases students' reading comprehensions. For the experimental group the increase of reading comprehensions score (post-test) in comparison with the control group can be considered.

The ANCOVA results indicated that pre-test scores were a statistical covariate with a large effect size $(\mathrm{F}(1,60)=43.6$, $p=.43$, partial eta-squared $=.71$, power $=1)$. This means that pre-test scores had a significant effect on how the participants performed on the post-test. The value of the partial eta squared indicates that $71 \%$ of students' ability to answer reading comprehensions question by the use of socio/affective strategy. One explanation for this strong effect is that students used the socio/affective strategies to determine their reading comprehension. On the other hand, the obtained partial eta-squared indicated that using socio/affective strategies accounted for $71 \%$ of the variability in the reading comprehension scores of the experimental group. Therefore, the findings of the study could be considered strong enough for the purpose of generalization. Furthermore, the high power obtained indicated that the conclusion to reject the null hypothesis was correct with a strong probability. As a result, the higher mean obtained by the experimental group on the post-test indicated that using socio/affective strategies had a significant effect on EFL learners' reading comprehension. In addition, by taking the post and pre-test into account, we can conclude that the experimental group's mean increase in the post test is more significant than the control group's mean increase in the post test.

Table 6. The summary of Analysis Covariance (ANCOVA) in the Post-test Achievement Scores

Group

Dependent Variable: POSTMARK

\begin{tabular}{lllll}
\hline & & & 95\% Confidence Level & \\
\hline Group & Mean & Std. Error & Lower Bound & Upper Bound \\
\hline Control & $27.941 \mathrm{a}$ & .847 & 26.244 & 29.637 \\
Experimental & $42.259 \mathrm{a}$ & .847 & 40.563 & 43.956 \\
\hline
\end{tabular}

a. Covariates appearing in the model are evaluated at the following

Values: PREMARK= 27.8333

A further comparison was made between the differences in post and pre test scores. Both experimental and control groups took a post-test for reading comprehension. In order to analysis of data covariance (ANCOVA) test was completed which included post-test score as the dependent variable, socio/affective strategy as the independent variable, and pre-test score as a covariate significance. Table 6 shows that there was a significant main effect of treatment on reading comprehension of learners $(\mathrm{F}(1)=43.68 ; \mathrm{P}<.05)$. The table also reveals a significant main effect of group (F (1) $=43 / 95 ; \mathrm{P}<.05)$ was found. The table describes the direction of observed significance in the analysis of covariance presented in Table 6. However, the difference in the mean scores of experimental group and the control group is not significant.

The results of ANCOVA scores are presented in the mean score and the standard deviation in the control group were (M $=27.94, \mathrm{SD}=.847)$ and the mean score and the standard deviation in the experimental group were $(\mathrm{M}=42.25, \mathrm{SD}$ $=.847$ ), which shows that there is significant difference between two groups regarding the post-tests. Reading scores in the experimental group has developed more than the control group. As Table 6 shows there are significant differences between control and experimental group in the mean score and standard deviation of reading performance in post-test.

RQ: Is there any relationship between social/affective strategies as positive strategy on reading comprehension? 
H0: There is no relationship between social/affective strategies as positive strategy on reading comprehension.
$\mathrm{H}$ : There is relationship between social/affective strategies as positive strategy on reading comprehension.

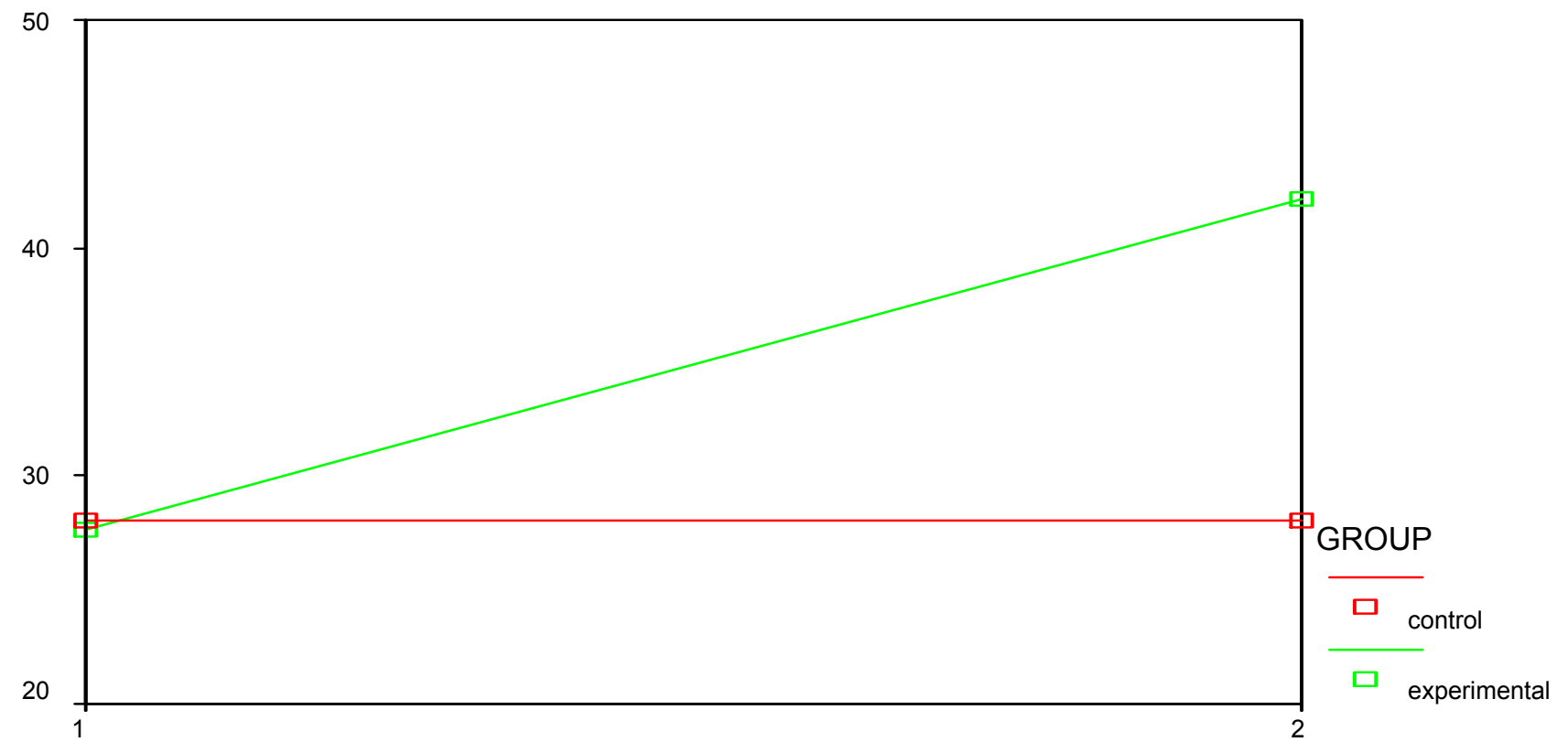

FACTOR1

Figure 1. Means plots of increase in mean value from the pre to the post tests in experimental and control groups.

Figure 1 represents the experimental groups' mean value increase from the post-test to the post-test. As the figure shows, the experimental group's increase in its mean value from the pre-test to the post-test is clearly sharper than the implicit group's increase in its mean value from the pre-test to the post- test.

\section{Discussion}

The aim of the present study was to determine the relationship between socio/affective strategy and reading comprehension in Iranian intermediate EFL learners. This study was conducted by giving placement test to 60 learners, which was based on the Oxford University Press and University of Cambridge Local Examinations Syndicate, which composed of 60 questions. Then, five reading passages extracted from Longman complete course for the TOEFL test by Deborah Phillips were applied.

Focus on socio/affective strategy and raising reading comprehension and according traditional socio/affective views, current views on reading development recognize the relevance of socio-affective factors. Anderson (1999) includes building motivation in his strategies for teaching second language reading. Therefore, the aim of this study was to fill a portion of this gap in EFL acquisition research. It seems that EFL students can become more interested in and ready for their reading comprehension if they realize that the focus of attention and interest is upon themselves as intelligent individuals and effective learners. With socio/affective learning, students can realize that they do not necessarily need to work more, but simply need to be more aware of socio/affective factors, use reading comprehension better, and organize their reading more effectively. Learners, thus, can be led into a process of self-discovery as successful learners who can and want to exploit their inner attributes and their social skills. With socio-affective training, EFL teachers have an additional tool that helps them to get to know learners individually and give them "learning-to-learn" tools that are useful both for their present life in class and for their future life outside the classroom. Instead of focusing on finding the best method or approach, the EFL field should devote time and energy to instructing EFL learners to be better informed about and prepared for their reading comprehension. In the long run, this kind of instruction can empower students by making them feel that they can experiment with their socio/affective strategy and, ultimately, take control of their own reading comprehension. Accordingly, the research question of this study was that "is there any relationship between socio/affective strategy and reading comprehension in EFL learners in intermediate levels?"

The SPSS software was used to analyze obtained data, which were consisted of descriptive statistics and analytical method (ANCOVA and Kolmogorov-Smirnov) as well as used. On the other hand, findings of the descriptive statistic were shown as tables and plots. Therefore, the present chapter comprehensively covers the findings of the conducted research in regards to its research questions.

\subsection{Summary of the Main Findings}

The findings of this thesis are in line with Vygotsky (1986), study which explored all human activities including teaching 
and learning activities are available in the social relationships among participants. According to the findings of their study, the participants showed significant gains in socio/affective strategies and reading comprehension. The findings of this study also support the findings of a study conducted by Choi (2011), who found 50 Korean EFL college learners results indicated that the experimental group improved in translating sentences rather than words.

Finally, within the broader framework of experimental and control groups focus on reading comprehension, the results of this thesis, which prove the superior role of socio/affective strategies on reading comprehension which, are backed by the results of the studies conducted by Simsek and Balaban (2010) who found a positive relation between the use of socio/affective strategies in promoting L2 learners' reading comprehension. For Solé (2005), reading comprehension are procedures involving goals, planning actions to achieve them, how to evaluate them and a possible change. For her, it is necessary to teach strategies if we want to achieve reading comprehension. Therefore, strategies are taught or not taught, learned or not learned. Moreover, reading comprehension are considered high order procedures where cognition, metacognition, and socio/affective processes play an important role. That is, a strategic mind has a capacity to represent and analyze problems and a flexibility to find solutions (pp. 59-60).

\subsection{Responding to the Research Questions}

RQ1: Are there any differences between control and experimental groups on the result of placement test?

H01: There are no differences between control and experimental groups on the result of placement test.

H1: There are differences between control and experimental groups on the result of placement test.

Accordingly, the research question of this study was that "are there any differences between control and experimental groups on the result of placement test?" dealing with investigating the differences between control and experimental groups the result of the placement test demonstrated in chapter 4,both experimental and control groups were homogenous in their placement test, on the other hand, it could be inferred that there is no noticeable differences exist among control and experimental groups at the same time in placement test. At this part of study, the researcher is supposed to reply the following hypotheses: there are no differences between control and experimental group on the result of placement test. Therefore, the researcher would like to apply alternative hypothesis in order to answer the proposed hypothesis.

RQ: Are there any differences between pre-test and posttest results on experimental groups on reading comprehensions?

H0: There are no differences between pre-test and post test results on experimental groups on reading comprehensions.

$\mathrm{H}$ : There are differences between pre-test and post-test results on experimental groups on reading comprehensions.

Also, according to the comparison made between the result of the post-test and the pre-test via paired samples t-test in experimental group, it was discovered that both pre-test and post-test had significantly positive effects on reading comprehension. In this respect, the post-test discrimination improved from 27.66 on the pre-test to 43.13 on the post-test. On the other hand, the statistical task is not rejecting the alternative hypothesis and show that there are differences between pre-test and post-test result in experimental group on reading comprehension.

RQ: Are there any differences between pre-test and posttest results on control groups on reading comprehensions?

H0: There are no differences between pre-test and post-test results on control groups on reading comprehensions.

$\mathrm{H}$ : There are differences between pre-test and post-test results on control groups on reading comprehensions.

Also, according to the comparison made between the result of the post-test and the pre-test via paired samples t-test in control group, it was discovered that both pre-test and posttest had not significantly positive effects on reading comprehension. In this respect, the post-test discrimination is not improved. The researcher would like to apply null hypothesis in order to answer the proposed hypothesis. The null hypothesis states that there is no differences between pre-test and post-test in control group on reading comprehension. Moreover, as previously confirmed by Curren (1972), socio/affective strategies are the major characteristics of more humanistic approach to language teaching including community language teaching.

RQ: Is there any relationship between social/affective strategies as positive strategy on reading comprehension?

H0: There is no relationship between social/affective strategies as positive strategy on reading comprehension.

$\mathrm{H1}$ : There is relationship between social/affective strategies as positive strategy on reading comprehension.

However, based on the results of the statistical analysis, ( dependent samples t-test in the post- test, independent samples t-test in the mean of the differences of the scores in the pre and post-test, and ANCOVA), it was discovered that the experimental group statistically made a more significant improvement than the control group after treatment. From this point it is concluded that the experimental group had significantly and meaningfully more positive effects than the control groups in the reading comprehension. These findings lead to the rejection of null hypothesis of this study which stated that there is no relationship between social/affective strategies and reading comprehensions. So, it is concluded that social/affective strategies has positively more significant effects on reading comprehensions.

\subsection{Pedagogical Implications}

According to the results, the following pedagogical implications were provided. The findings of this study carry useful implications for teachers, curriculum planners, and in classroom activities. The results of this study recommend the incorporation and injection of socio/affective strategies and reading comprehension in EFL learners. By so doing, 
curriculum planners and teachers will expedite and enhance EFL learners' ability in reading comprehension. Unfortunately, some learners are not fully aware of the role of socio/affective strategies on reading comprehension. In addition, socio/affective strategies are also a tool in empowering learners learning which can facilitate and successfully achieved through efficient communication. Moreover, some learners reported that they had not been informed about the existence of socio/affective strategies, so they were not able to use it. Consequently, teacher should help learners in order to cultivate and develop their awareness of socio/affective strategies. Besides, they should be informed about the appropriate use of socio/affective strategies in the specific context and situation.

Furthermore, the development of socio/affective strategies helps learners in order to deal with language skills such as reading comprehension more easily. Besides, it should be taken into consideration that reading comprehension is an indispensible tool in describing and explaining the development of foreign or second language learning. Furthermore, noticeable relationship in the utilization of socio/affective strategies and reading comprehension achieved by upper intermediate learners should be taken into account.

With better understanding of concepts of socio/affective strategies and reading comprehension, teachers and learners can better understand the situation of EFL learning. Moreover by encouraging appropriate beliefs and providing effective instruction of social/affective strategies according to learners' needs and situations, teachers can teach English more efficiently. In order to comprehend the learners' beliefs and attitudes about social/affective strategies and reading comprehension, some materials and methods can be used in the regular curriculum and in classroom activities. For example, by using social/affective strategies in the classroom not only they could help learners in order to promote their awareness of reading comprehension. Learners are asked to deal with various tasks, so familiarity with social/affective strategies can facilitate their process of reading comprehension and lead to better learning. Another implication of the present study is linked to the gap, which exists among social/affective strategies and reading comprehension. In this new horizon, teachers can reconsider their negative disposition against or their lack of attention to the socio/affective strategies.

The present study found a significant relationship between socio/affective strategies and reading comprehension. Teachers should try to help learners to develop a positive belief and attitude towards socio/affective strategies as rudimental factors, which facilitate and flourish the reading comprehension. Besides, teacher should eradicate the negative beliefs and attitudes towards socio/affective strategies and reading comprehension. Moreover, teachers should allow learners to become fully aware of their preferred socio/affective strategies and realize problems when they face in reading, formulate questions, and ask teacher or peers the questions for clarification and specially help them become more responsible to meet their learning goals. That is, teachers are able to help learners become successful learners in reading comprehension by training them in using the right socio/affective strategies. Training the learners with socio/affective strategies, the objectives and goals could be achieved. Then, they will likely become more independent in reading comprehension. Due to the significant role of socio/affective strategies, it is expected that the attitudes of teachers and learners towards socio/affective strategies and reading comprehension be up-dated. Furthermore, learners are asked to develop their scope of socio/affective strategies because of the significant relationship, which exists between socio/affective strategies and reading comprehension that lead to better learning of reading comprehension. Instruction in socio-affective strategies can promote and facilitate the process of reading comprehension by stimulating students to have deeper thoughts about their learning and reading states as well as the socio/affective factors they had brought into the learning process, which can ultimately encourage them to plan more effective reading methods and directions for future efforts. Socio/affective factors should not be regarded as simple instructional strategies or techniques, but as a smarter way of teaching foreign languages that does not require a total revamping of teaching practices. Rather, EFL teachers can complement their daily work with the use of socio-affective materials and activities aimed at helping learners better understand and experience the social and affective side of their learning and reading process. Working with socio/ affective factors can ultimately help EFL teachers create a comfortable classroom atmosphere in which students can develop a deeper understanding of the nature of reading comprehension.

The beliefs, attitudes, and anxieties of EFL students are constructed based on previous experiences with activities and materials related to EFL language learning. Therefore, teachers should be aware of these affective factors especially when using learner-centered approaches or strategy-based instruction, since students may come to the class with erroneous preconceptions, negative experiences, or with limited exposure to these methods.

\subsection{Limitations of the Study}

During the research, some infeasibilities act as obstacles in the process of research. Regarding the limitation of this study, it must be mentioned, at the outset, that this study was conducted in an Iranian context in upper intermediate level. So, whether learners with differently levels are open to further investigation. Second, this study concentrated on socio/affective strategies it is open to reservation and investigation if other strategies such as, cognitive or metacognitive strategies are also considered. Third, this study was carried out on upper intermediate EFL learners. So, it is useful to re-conduct this across other proficiency levels on both males and females. Last but not the least, this study was administered to a sample size of almost 60 participants $(\mathrm{N}=60)$. It is recommended that this research be conducted on 
a larger sample in order to achieve more reliable and generalizable results.

\subsection{Suggestions for Further Research}

The researcher conducted his research regarding socio/affective strategies. However, other researchers can conduct the research by considering other taxonomies of learning strategies. Due to some infeasibility, the researcher was not able to include intervening variables such as gender and age in his research; however, it is suggested that such intervening variables are included in the further studies.

\section{Acknowledgements}

I could not have completed this essay, or graduate university, without the encouragement, guidance, and care from a core group of people. First and foremost, my beloved parents and wife; Besides, my sister Miss Simin Zeynali who helped me so much and also my best friends especially $\mathrm{Mr}$. Fariborz Pishdadi who has provided tremendous support throughout my post graduate studies. Words do little to convey how thankful I am to all of them. My great professors have consistently warmed by heart, and taught me to appreciate the little things. I am deeply indebted to my great professor Dr. Sabouri for giving me the positive energy and hope to study and do the research. He is the best supervisor a student could ever ask for. Finally, I'd like to thank Dr. Farahman Farrokhi, Dr. Mohammad Zohrabi, for their encouragements and continued assistances and giving me the opportunity to become aware of my infinite ignorance.

\section{References}

[1] Alderson, J. C. (2000). Assessing reading. New York: Cambridge University Press.

[2] Alderson, J. C., \& Urquhart, A. H. (1985). The effect of students' academic discipline on their performance on ESP reading tests. Language Testing, 2, 192-204.

[3] Anderson, N. J. (1991). Individual differences in strategy use in second language reading and testing. The Modern Language Journal, 75, 460-472.

[4] Abbott, M.L. (2006). ESL Reading Strategies: Differences in Arabic and Mandarin speaker test performance. Language Learning, 56(4): 633-670.

[5] Abitat, L. 2007. Reading strategies. http://www.mcps.k12.md.us/departments/isa/staff/

English/reading strategies.htm. Accessed on 17 August 2007.

[6] Adams M.J. 1990. Beginning to read: Thinking and learning about print. Cambridge, MA: Harvard University Press.

[7] Adeyemi, D. 2008. Bilingual education: Meeting the challenges of diversity in Botswana. Nordic Journal of African Studies, 17(1): 20-23.

[8] Alderson, J.C. \& Urquhart, A.H. 1988. This test is unfair: I'm not an economist, in Interactive approaches to second language reading. Edited by P.L. Carrell, J. Devine and D.E Eskey.Cambridge: Cambridge University Press: 168-182.
[9] Al-Jarf, R. 2006. Language student enrollment in EFL programs: Challenges and consequences.

[10] Barnett, M. A. (1986). Syntactic and lexical/semantic skill in foreign language reading: Importance and interaction. The Modern Language Journal, 70, 343-349.

[11] Barry, S., \& Lazarte, A. A. (1998). Evidence for mental models: How do prior knowledge, syntactic complexity, and reading topic affect inference generation in a recall task for nonnative readers of Spanish? The Modern Language Journal, 82, 176-193.

[12] Beck, I., McKeown, M., Sinatra, G., \& Loxterman, J. (1991). Revising social studies text from a text-processing perspective: Evidence of improved comprehensibility. Reading Research Quarterly, 26, 251-276.

[13] Bernhardt, E. B. (1991). Reading development in a second language. Norwood, NJ: Ablex.

[14] Bernhardt, E. B. (2005). Progress and procrastination in second language reading. Annual Review of Applied Linguistics, 25, 133-150.

[15] Block, E. L. (1986). The comprehension strategies of second language readers. TESOL Quarterly, 20, 463-494.

[16] Block, E. L. (1992). See how they read: Comprehension monitoring of L1 and L2 readers. TESOL Quarterly, 26, 319343.

[17] Booth, J. R., Perfetti, C. A., \& MacWhinney, B. (1999). Quick, automatic, and general activation of orthographic and phonological representations in young readers. Developmental Psychology, 35, 3-19.

[18] Brantmeier, C. (2004). Building a comprehensive theory of adult foreign language reading: A variety of variables and research methods. Southern Journal of Linguistics, 27, 1-7.

[19] Brantmeier, C. (2006). Toward a multicomponent model of interest and L2 reading: Sources of interest, perceived situational interest, and comprehension. Reading in a Foreign Language, 18, 89-115.

[20] Brown, R., Pressley, M., Van Meter, P., \& Schuder, T. (1996). A quasi-experimental validation of transactional strategy instruction with low-achieving second-grade students. Journal of Educational Psychology, 88, 18-37.

[21] Carrell, P. L. (1985). Facilitating ESL reading by teaching text structure. TESOL Quarterly, 19, 727-752.

[22] Carrell, P. L. (1987). Content and formal schemata in ESL reading. TESOL Quarterly, 21, 461-481.

[23] Carrell, P. L. (1992). Awareness of text structure: Effects on recall. Language Learning, 42, 1-20.

[24] Carrell, P. L., Gajdusek, L., \& Wise, T. (1998). Metacognition and EFL/ESL reading. Instructional Science, 26, 97-112.

[25] Carver, R. (1992). Reading rate: Theory, research, and practical implications. Journal of Reading, 36, 84-95.

[26] Carver, R. (1993). Merging the simple view of reading with rauding theory. Journal of Reading Behavior, 25, 439-55.

[27] Chen, H. (1998). Yingyu shuiping dui Zhongguo Yingyu xuexizhe lijie Yingyu jufa qiyi de zhiyue zuoyong [Constraints of English proficiency on understanding English ambiguous 
sentences in Chinese EFL learners]. Modern Foreign Languages, 2, 1-16.

[28] Chen, H-C., \& Graves, M. F. (1995). Effects of previewing and providing background knowledge on Taiwanese college students' comprehension of American short stories. TESOL Quarterly, 29, 663-686.

[29] Cohen, A. (1998). Strategies in learning and using a second language. London: Longman.

[30] Commander, N. E., \& Stanwyck, D. J. (1997). Illusion of knowing in adult readers: Effects of reading skill and passage length. Contemporary Educational Psychology, 22, 39-52.

[31] Evans, E. E. (1988). "Advanced" ESL reading: Language competence revisited. System, 16, 337-346.

[32] Flavell, J. H. (1978). Metacognitive development. In J. M. Scandura \& C. J. Brainerd (Eds.), Structural/Process theories of complex human behavior (pp. 213-245). The Netherlands: Sijthoff and Noordhoff.

[33] Fraser, C. A. (2004). Reading fluency in a second language. The Canadian Modern Language Journal, 61, 135-160.

[34] Gibson,E,\& Levin,E,(1975),The psychology of reading,Cambridge,MA:M.I.T.Press.

[35] Goodman, K. S. (1967). Reading: A psycholinguistic guessing game. Journal of the Reading Specialist, 6, 126-35.

[36] Grabe, W. (1999). Developments in reading research and their implications for computer-adaptive reading assessment. In M. Chalhoub-Deville (Ed.), Issues in computer-adaptive testing of reading proficiency (pp. 11-48). Cambridge, UK: Cambridge University Press.

[37] Grabe, W., \& Stoller, F. (2002), op cit., p. 19; Verhoeven, L., \& Snow, C. 2001,Literacy and Moti-vation: Reading Engagement in Individuals and Groups, (Mahwah, NJ: Lawrence Erlbaum Associates Publishers), p. 2

[38] Grabe, W., \& Stoller, F. L. (2002). Teaching and researching reading. London: Longman.

[39] Gregory, S. (1994). The effect of metacognitive knowledge on local and global monitoring. Contemporary Educational Psychology, 19, 143-154.

[40] Haenggi, D., \& Perfetti, C. A. (1992). Individual differences in reprocessing of text. Journal of Educational Psychology, 84, 182-192.

[41] Hammadou, J. (1991). Interrelationships among prior knowledge, inference, and language proficiency in foreign language reading. The Modern Language Journal, 75, 27-38.

[42] Hazenburg, S., \& Hulstijn, J. H. (1996). Defining a minimal receptive second language vocabulary for non-native university students: An empirical investigation. Applied Linguistics, 17, 145-163.

[43] Hopkins, N. M., \& Mackay, R. (1997). Good and bad readers: A look at the high and low achievers in an ESP Canadian studies reading and writing course. The Canadian Modern Language Review, 53, 473-490.

[44] Hosenfeld, C. (1977). A preliminary investigation of the reading strategies of successful and non-successful second language learners. System, 5, 110-123.
[45] Hosenfeld, C. (1984). Case studies of ninth grade readers. In J. C. Alderson \& A. H. Urquhart (Eds.), Reading in a foreign language (pp. 231-240). London: Longman.

[46] Just, M. A., \& Carpenter, P. A. (1987). The psychology of reading and language comprehension. Boston, Mass.: Allyn \& Bacon.

[47] Karen, Z., \& Evans, C. N. (1993). Rereading to understand: The role of text coherence and reader proficiency. Contemporary Educational Psychology, 18, 442-454.

[48] Kern, R. G. (1994). The role of mental translation in second language reading. Studies in Second Language Acquisition, 16, 441-461.

[49] Laufer, B. (1989). What percentage of text-lexis is essential for comprehension? In C. Lauren \& M. Nordman (Eds.), Special language: From humans thinking to thinking machines, (pp. 316-323). Philadelphia, PA: Multilingual Matters.

[50] Liu, Z., \& Bever, T. G. (2002). Jufa fenxi zai waiyu yueduzhong de zuoyong [An experimental study of the function of syntactic analysis in reading comprehension]. Foreign Language Teaching and Research, 34, 219-224.

[51] Long, D. L., Seely, M. R., Oppy, B. J., \& Golding, J. M. (1996). The role of inferential processing in reading ability. In B. K. Britton \& A. C. Graesser (Eds.), Models of understanding text (pp. 189-214). Hillsdale, NJ: Erlbaum.

[52] Long, D. L., \& Chong, J. L. (2001). Comprehension skill and global coherence: A paradoxical picture of poor comprehenders' abilities. Journal of Experimental Psychology: Learning, Memory, and Cognition, 27, 1424-1429.

[53] Lu, S. (1999). An investigation into EFL reading processes: Reading effectiveness, inference construction, metacognitive strategy. Unpublished MA dissertation, Zhejiang University, China.

[54] Meyer, B. J. F., \& Rice, G. E. (1982). The interaction of reader strategies and the organization of text. Text, 2, 155-92.

[55] Meyer, B. J. F., \& Rice, G. E. (1984). The structure of text. In P. D. Pearson, R. Barr, M. L. Kamil, \& P. Mosenthal (Eds.), Handbook of reading research (pp. 319-352). New York: Longman.

[56] Ministry of Education. (2001). Yingyu kecheng biaozhun [National English curriculum standards for general education]. Beijing: Beijing Normal University Press.

[57] Nassaji, H. (2003). Higher-level and lower-level text processing skills in advanced ESL reading comprehension. The Modern Language Journal, 87, 261-276.

[58] Pang, J. 2008. Research on good and poor reader characteristics: Implications for L2 reading. Research in a Foreign Language, 20(1): 1-9

[59] Pang, J., Zhou, X., \& Fu, Z. (2002). English for international trade: China enters the WTO. World Englishes, 21, 201-216.

[60] Paris, S. G., Wasik, B. A., \& Turner, J. C. (1991). The development of strategic readers. In R. Barr, M. L. Kamil, P. Mosenthal, \& P. D. Pearson (Eds.), Handbook of reading research, (Vol. 2, pp. 609-640). Mahwah, NJ: Lawrence Erlbaum Associates. 
[61] Parry, K. (1991). Building a vocabulary through academic reading. TESOL Quarterly, 25, 629-653.

[62] Perfetti, C. (1985). Reading ability. New York: Oxford University Press.

[63] Pichette, F., Segalowitz, N., \& Connors, K. (2004). Impact of maintaining $\mathrm{L} 1$ reading skills on $\mathrm{L} 2$ reading skill development in adults: Evidence from speakers of Serbo-Croatian learning French. The Modern Language Journal, 87, 391-403.

[64] Pressley, M. (1998). Reading instruction that really works. New York: Guilford Press.

[65] Rayner, K. (1997). Understanding eye movements in reading. Scientific Studies of Reading, 1, 317-339.

[66] Reynolds, R. E., Shepard, C., Lapan, R., Cynthia K., \& Goetz, E. T. (1990). Differences in the use of selective attention by more successful and less successful tenth-grade readers. Journal of Educational Psychology, 82, 749-759.

[67] Schoonen, R., Hulstijn, J., \& Bossers, B. (1998). Metacognitive and language-specific knowledge in native and foreign language reading comprehension: An empirical study among Dutch students in grades 6, 8 and 10. Language Learning, 48, 71-106.

[68] Sheorey, R., \& Mokhtari, K. (2001). Differences in the metacognitive awareness of reading strategies among native and non-native readers. System, 29, 431-449.

[69] Smith, F. (1973). Psycholinguistics and reading. New York:
Holt, Rinehart \& Winston.

[70] Spires, H. A., \& Donley, J. D. (1998). Prior knowledge activation: Inducing engagement with informational texts. Journal of Educational Psychology, 90, 249-260.

[71] Stanovich, K. E. (1980). Towards an interactive-compensatory model of individual differences in the acquisition of literacy. Reading Research Quarterly, 16, 32-71.

[72] Stanovich, K. E. (2000). Progress in understanding reading: Scientific foundations and new frontiers. New York: Guilford Press.

[73] Upton, T. A., \& Lee-Thompson, L. (2001). The role of the first language in second language reading. Studies in Second Language Acquisition, 23, 469-495.

[74] West, R. F., Stanovich, K., \& Cunningham, A. (1995). Compensatory progresses in reading. In R. Dixon \& L. Backman (Eds.), Compensating for psychological deficits and declines: Managing losses and promoting gain (pp. 275-296). Hillsdale, NJ: Erlbaum.

[75] Yang, X., \& Zhang, W. (2002). Yuanrenzhi yu Zhongguo daxuesheng Yingyu yuedu lijie xiangguan yanjiu [The correlation between metacognition and EFL reading comprehension of Chinese college students]. Foreign Language Teaching and Research, 34, 213-218.

[76] Zvetina, M. (1987). From research to pedagogy: What do L2 reading studies suggest? Foreign Language Annals, 20, 233 238 . 